\title{
The Semiosis of Architectural Identity in The Witcher 3
}

\author{
Gabriele ARONI \\ School of Interior Design \\ Faculty of Communication and Design \\ Ryerson University, Canada \\ E-mail: gabriele.aroni@ryerson.ca
}

\begin{abstract}
The representation of space in digital games is symbolic and rule-based rather than uniquely spatial, thus virtual space bears significance, be it for narratological reasons, or for more stringent reasons of gameplay. Virtual architecture might be more apt to be analyzed as a system of signs, as, unlike real architecture, its very existence is for the communication of information to the player, and the communicative aspect is no mere accident or addition to other functions. We will utilize the semiotic frameworks put into place by Umberto Eco as regards architecture as mass communication and Brian Upton's as concerns digital games, with the concept of "ludic sign", to "read" the architectural design of Polish game The Witcher 3, as the role of architecture in world-building is of important metaphorical and symbolic value to the game. The Witcher 3 adopts a particular style, which diverges from the standard fantasy settings, and the dichotomy between the main game and its expansion Blood \& Wine, set in a faux Italy/Southern France, is a perfect example of how virtual architecture carries a symbolic value and a communicative aspect and is not a mere backdrop for the action.
\end{abstract}

Keywords: Semiotics; Digital games; Virtual architecture; Cultural identity; Communication.

Acknowledgements: This research was supported by the Social Sciences and Humanities Research Council of Canada.

A draft version of this paper was presented at the Semiosis in Communication: Differences and Similarities conference held in Bucharest, Romania, on 14-16 June 2018. 


\section{Introduction}

This article explores how virtual architecture can be used as a vector for expressing cultural identity in digital games using the game The Witcher 3: Wild Hunt (CD Projekt RED, 2015) as a case study. How can virtual architecture communicate a cultural identity to players? To answer this question we will resort to the tools of semiotics in order to investigate which architectural signs the artists and developers of the game employed in order to express their vision. The Witcher 3 is a digital game developed in Poland based on the novels and short stories of famous Polish author Andrzej Sapkowski, and part of what determined its success is its distinctive setting. Through a semiotic analysis of its architecture we will be able to understand how The Witcher's setting differs from those of other digital role-playing games and why players perceive it as unique. Moreover, within the game itself, there are noticeable architectural and stylistic differences, thanks to its expansion Blood \& Wine (CD Projekt RED, 2016) which adds a new region with a completely distinct design. The Witcher 3 is thus an ideal case study to analyze the communicative aspect of virtual architecture both as a mean to establish a distinctive identity for the game, as well as to visually separate different environments within the same game.

What makes many games so engrossing, aside from the more obvious ludological aspect per se, is the visual aspect that turns the experience of visiting the spaces represented engaging and aesthetically rewarding. Henry Jenkins $(2004,122)$ affirms that:

[t]he early Nintendo games have simple narrative hooks - rescue Princess Toadstool - but what gamers found astonishing when they first played them were their complex and imaginative graphic realms, which were so much more sophisticated than the simple grids that Pong or Pac-Man had offered us a decade earlier.

Grant Tavinor $(2009,174)$ goes so far as to conflate the artistic status of digital games with their visual properties, stating that "they do have perceptual and formal structures that are the object of an aesthetic and interpretive engagement in much the same way as other artworks" and "employ much of the same aesthetic vocabulary" $(2009,180)$. The same applies to the players, who, in Tavinor's opinion, share aesthetic interests comparable to traditional art appreciators $(2009,180)$.

Most digital games display extremely detailed three-dimensional sceneries that can usually be explored in a first- or third-person perspective - i.e. as if the player were looking through the character's eyes or from a virtual camera hovering some distance over the character - and the point of view is manipulated in real time, giving the same flexibility that we would have when visiting an actual place. Additionally, recently released virtual reality headsets, such as the Oculus Rift and HTC 
Vive, enable us to have perception of depth as well as give us the advantage of not just seeing the limited portion of the screen but a much wider field of view around the player. Artists and modellers who create digital game environments have thus to deal with the great freedom players will have within their creations. As such, they are forced to use a language common to architects such as perspective, flow of the space, perceived size, and so on. In digital game architecture, as much as in physical architecture, many aspects of the space are linked to their usage. As such, the semiotics of architecture of digital game spaces is essential to understand how the game itself exists and is played. As Joaquìn Siabra-Fraile $(2009,70)$ explains with respect to the game Ico (Team Ico, 2001): "[a] story, such as the one told in Ico, is unfeasible without the space of doors, chains, cornices and stairways that constitute the castle; in the same way that the castle is only interesting insofar as it allows the story to unfold". Pierre Pellegrino and Emmanuelle Jeanneret (2009, 271), in Meaning of Space and Architecture of Place, affirm that "space is semiotic as much as pragmatic" and that "[a]s a monument of architecture, the building is a semiotic object of connotation, of which the shape taken by the signifier enters into measured relation with that taken by the signified" $(2009,284)$.

All visible phenomena that can be interpreted as indexes can be considered conventional signs, as long as there is a semiotic process of understanding and decoding the sign. (Eco, 1968/2016, sec. B.1.I.3) So: a bright light makes me close my eyes, but it is just a natural impulse, there is no exchange of meaning. But if the light is pink and from the east and I know the code, then I can 'read' the light as a message for the sun about to rise. The same in architecture and video games: many signs are easily interpreted by people who know the code, whereas for someone new it might not come naturally. Digital games architecture is usually an iconic sign, a sign that resembles visually its original counterpart, i.e. a house in a game will look like a house in the real world in order to convey the meaning of 'house'.

Umberto Eco (1997, 187), in particular, brings forth architecture as a form of mass communication, whereby we can easily draw parallels between the points he makes and architecture in digital games:

1. "Architectural discourse generally aims at mass appeal". As the majority of digital games aims to appeal to as wide a market as possible, their architectural design has to appeal to a wide audience as well.

2. "Architectural discourse is psychologically persuasive" as "one is prompted to follow the 'instructions' implicit in the architectural message". This is even more evident in digital game architecture, as the level design must tell the player where to go and what to do.

3. "Architectural discourse is experienced inattentively" unlike, for example, works of art that we observe with attention. In real life, you can just stroll in a building or study it attentively; the same principle applies to digital games: 
generally, architecture is, if not a backdrop, at least an element that the player does not focus on too much, unlike, for instance, an enemy on screen, or when looking for traps.

4. "[A]rchitecture fluctuates between being rather coercive, implying that you will live in such and such a way with it, and rather indifferent, letting you use it as you see fit." As mentioned above in 2 and 3, this also applies to digital games: even within the same game, architecture can fluctuate between being a backdrop, and thus indifferent, for example during the movement between two points of interest in an open-world RPG, to a more coercive role, such as inside a dungeon or in a corridor in a first-person shooter (FPS).

\section{Theoretical framework}

For the purpose of this article, we will use the theory developed by Umberto Eco $(1997,177)$, according to whom architecture has two semiotic functions: a primary denotative one and a secondary connotative one. The primary denotative function is based on the very form of architecture, for example a flight of stairs denotes its purpose as allowing to ascend or descend without the need of any additional sign, but in virtue of its very form. The secondary connotative function rests on the primary one and conveys additional messages based on external linguistic or cultural codes. A staircase of a certain size and material can connote its role within the building as the main or secondary staircase, but users need to possess the correct code to understand its meaning: knowing if the material is rare or expensive or if the size is unusual for a staircase.

It is evident that the secondary connotative function can be absent or incidental in real architecture. A dilapidated building connotes and idea of lack of use and maintenance, but it is hardly a conscious design decision. In digital games, however, what would be an accidental sign in real architecture is a conscious design decision. Elements such as disrepair do not accumulate naturally with time, but are rather designed, and as such they are placed with a precise intent in mind in order to communicate to players.

In digital games, we can thus understand virtual architecture as a system of signs that communicates to the player, and look at it through a semiotic lens. Brian Upton $(2015,157)$ points out that, "[i]t is important to accommodate semiotics within our play-based critical framework because so much of play involves the exchange of symbols between players." For his part, Espen Aarseth $(2001,163)$ states that the representation of space in computer games is "symbolic and rulebased" rather than uniquely spatial. Of course, many of these signs are embedded in other forms of communication within the game, such as the interface, dialogues and texts; however, it is evident that the architectural design does play a role in the communicative as well as aesthetic aspects of the game. 
For Upton $(2015,170)$, the aesthetic experience of digital games is a semiotic process, but it differs from the traditional semiotic analysis of texts for it does not have a direct correspondence between signs, as in the semiotic theories of, for example, Saussure and Peirce, but rather a "convoluted and indirect" path established by the designer that leads to the intended meaning, where the navigation of this indirect and convoluted path is the enjoyment in itself, as much as we enjoy reading a book or listening to a symphony not just in order to arrive to its conclusion or meaning, but rather to enjoy the journey itself. This model of semiosis is what Upton $(2015,167)$ calls the ludic sign, where "there is no fixed relationship between signifiers and signified”. The meaning of architectural identity can be understood as a ludic sign, where "it's merely a tool for conceptualizing a transient causal linkage between pattern and constraint during a communicative event” $(2015,167)$. As Upton $(2015,167)$ explains "[i]f words sometimes appear to mean specific things, it's only because we often find ourselves in situations in which the reciprocal understanding of speaker and listener produces the desired evoked constraints", and the same can be said for architecture, virtual or real, where we interpret its signs based on a common cultural substrate.

\section{Methodology}

This article applies the outlined theories of Umberto Eco and Brian Upton to the digital game The Witcher 3: Wild Hunt (CD Projekt RED, 2015) to investigate how the virtual architecture in the game semiotically communicates with players.

The case study displays two main characteristics on an aesthetic and architectural level that makes it worthy of examination: 1. the European influence that permeates the whole game and sets it apart from many others, and 2. the difference between the areas of the main game, and its expansion Blood \& Wine. We are going to semiotically analyze how these characteristics are expressed through architecture, and how the messages intended by the developers are conveyed to the players. The design choices related to level design as concerns the ludological and technical aspects of the game are not going to be analyzed, as we shall solely focus on the architectural aspect and identity of The Witcher 3.

\section{Discussion}

The Witcher 3: Wild Hunt (CD Projekt RED, 2015) is the third entry of The Witcher trilogy of fantasy action role-playing games (RPG). The series is based on the Wiedźmin novels by Polish author Andrzej Sapkowski and has been running since 2007. The digital games series as a whole has sold more than 20 million units as of 2016, half of which came from the last entry (Makuch, 2016), The Witcher 3, and was the recipient of over 800 awards (thewitcher.com, 2016). The player impersonates Geralt of Rivia (Geralt z Rivii in Polish), the titular "witcher", a beast hunter with 
superhuman capabilities developed through training and body modifications at a young age.

The Witcher series draws heavily from Polish folklore in its themes and story, which is reflected in the game aesthetics as well (Dzik, 2017; Tomaszkiewicz, 2015). The Witcher 3 is the first game in the series to provide a large - around 136 square kilometers (Sayed, 2015) - freely explorable area to players with varied environments, from large cities to mountainous rocky islands inspired by Scandinavian fjords. The story of the game takes place during the invasion by the Nilfagaardian Empire of the Northern Kingdom, where the playable area is located, and thus displays a land at war, with a generally gloomy and harsh atmosphere, another characteristic of the series.

As a visual counterbalance to the main game, its expansion Blood \& Wine (CD Projekt RED, 2016) is set in the rich and seemingly peaceful duchy of Toussaint. The new locations display lush rolling hills and brightly colored cities, inspired by Italy and the south of France.

\section{RPGs and Identity}

Using architecture to communicate a geographical and communitarian identity is of course nothing new. Vitruvius in his treatise on architecture wanted to give the recently founded Roman Empire a proper, as in, local, 'Italic' rather than borrowed from the Greek tradition, architectural order. The Tuscan order, that Vitruvius devised from the tuscanicae dispositiones, the ancient Etruscan way of designing temples, was part of the larger plan of Augustus to counter the enormous influence that Greek culture still had over the Romans in many fields, including architecture, in the first century CE (Morolli, 2013, 40). Similar episodes can be found in many other eras, as well, such as when architect Brunelleschi, in the words of Giorgio Vasari $(1550 / 1986,299)$, brought back to $15^{\text {th }}$ century Florence the "good architecture" of classical forms, rather than the "German and barbarian" Gothic architecture that was being used at the time.

The main influences for RPGs are undoubtedly of Anglo-Saxon ancestry, starting with J.R.R. Tolkien's The Lord of the Rings (1954) as the prototype of most fantasy fiction, to Gary Gygax and Dave Arneson's tabletop role-playing game Dungeons \& Dragons (1974), which in turn borrowed heavily from The Lord of the Rings for its settings and look, and established many canons that are still followed today. Naturally, the former being a British product, and the latter an American one, the general aesthetic followed Anglo-Saxon styles. Digital games, as well, followed the same path, not only because they took inspiration from the aforementioned Dungeons \& Dragons both in mechanics and aesthetics, but also because the majority of the most important and influential role-playing digital games were developed mostly in North America, from the Ultima series (Origin Systems, 1981-1999) to 
the more recent Dragon Age (BioWare, 2009-2014). An exception are the Japanese role-playing digital games, which in fact are usually branded with their own acronym, JRPG instead of RPG, to differentiate them from the Western approach, in which they differ both in terms of gameplay mechanics as well as aesthetics, such as the long-standing series of Final Fantasy (Square, Square Enix, 1987-2019).

Instead, as mentioned earlier, The Witcher 3 draws its inspiration from Eastern Europe, and this approach was a point of distinction for the game, as explained by game director Konrad Tomaszkiewicz (2015): "We're proud we can show Polish nature and its atmosphere, unique to gaming, because most games offer cookiecutter worlds. Our team, by using folk themes, offers something one of a kind." The training of the artists involved in the development of the game played a part in the characterization as well, as explained by Jan Marek (Stec, Marek, Gollent, Tost, \& Tomaszkiewicz, 2018, 60), senior concept artist at CD Projekt RED: "Our artists brought up in Slavic culture were raised on works by the likes of Jan Matejko, Stanisław Wyspiański, Aleksander Gierymski, Olga Boznańska, and Jacek Malczewski, but I would classify that as visual knowledge, rather than direct references we used." The question that arises is thus the following: how does the architecture in the game transmit such messages?

\section{Novigrad}

The Witcher 3 starts with Geralt in White Orchard, where he rejoins his lover Yennefer. White Orchard is a small village set in a lush farm region: "Clear skies abound and the orchards' trees are bursting with white flowers. It takes a moment to notice the tell-tale signs of war: collapsed roofs, turned-over carts littering the roadside, and abandoned possessions strewn about neglected farmyards." (CD Projekt Red, 2015, 8) Even without dialogues, the player can infer what is going on in the game thanks to the messages delivered by the architecture.

As the player progresses in the story, s/he reaches the Free City of Novigrad, the biggest city in the game and one of the most characteristic scenarios. The city of Novigrad "is inspired by the trade settlements of northern Europe. Most buildings are made of brick, streets are paved, and most roofs (outside of the poor district, that is) are covered in tile rather than thatch" (CD Projekt Red, 2015, 37) in an attempt to differentiate the rich city from the poor and gloomy aspect of the Velen region described before, while at the same time setting the tone of Polish architecture. As stated by Eco $(1997,187)$ in regard to architecture as mass communication, it is "experienced inattentively", and digital games architecture is no different. The player does not focus directly on the architectural details of the city, nor do they play any part in actual gameplay, which consists mostly of conversations with various characters and fights against monsters. However, it is evident that the landscape and cityscape are a big part of what is actually seen at any time 
by the player on screen and affects how s/he moves and where s/he goes:

Architectural reference is the foundation of video game environments. It not only informs the visual design of roofs, buildings, or entire cities but, in working out how players should best navigate these constructions, their physical realities come to [be] part of the rhythm of these virtual worlds, and your journey through them. (Ballard, Domenech, \& Niepokolczycki, 2017)

Coming back to the example of the crown-stepped gables of the buildings in Novigrad, their semiotic meaning is not direct as in: crown-stepped gable $=$ Northern/Eastern European architecture. The shape and material of the crown-stepped gables, or the colored plastered facades, can be understood at a primary level, as a more direct, iconic sign of what they are, a series of construction materials arranged in a particular form and of a particular color. There are elements though that can be understood by possessing the necessary additional knowledge, for example the previously mentioned state of the city compared to the countryside: the paved roads, the well-maintained buildings are all signs of the condition of the city and what kind of environment the player finds her/himself in. This applies to the various districts in the city, the covering of the roofs is another architectural sign that quickly gives away the status of the buildings: neatly disposed tiles in the richer districts and thatch in the poorer ones. Of course, all these signs are combined with a plethora of information the player has access to: from dialogues with other characters in the game, to textual information about the world and its inhabitants, but even per se, the architectural signs are often sufficient to indicate information related to the story or on how to play the game. If the player is, for example, escaping from the authorities, $\mathrm{s} /$ he is most likely to find refuge in the rundown part of the city, rather than in the well-established district, and these sorts of signs are easily readable by looking at the architecture around her/him, similarly to what was stated by Eco $(1997,187)$ in regard to architecture as mass communication that is "psychologically persuasive".

The architecture in the city of Novigrad conveys a set of information that is "secondary" as concerns the actual gameplay but is indeed essential to convey a sense of place that characterizes the game and has arguably been part of its critical and commercial success. As mentioned, the architectural style of the city is reminiscent of northern/eastern European architecture, unlike the vast majority of fantasy RPGs on the market. In an interview with Jack Yarwood, David G. Ballard, level artist at Naughty Dog, explains that:

Reference is crucial for any and all artists, [...] For an environment artist, we need to draw inspiration from the historical and ever-evolving world of architecture and interior design. Reference supplies this inspiration, especially for locations that the artist might not have access to. (Ballard et al., 2017) 
The turreted city resembles cities such as Gdańsk, which is the main port of Poland on the Baltic sea, as much as Novigrad is the major port of the region in the game. The high-pitched roofs with the typical crow-stepped gables, buildings plastered in garish colors, all convey to the player the indication that $\mathrm{s} / \mathrm{he}$ is in a distinct location, which resonates with players who are able to recognize this style as well as players who may not directly link these architectural details to a specific location, but would be able to differentiate them from the usual stone or wooden buildings that populate other game locations.

\section{Beauclair}

The 2016 expansion to the base game, Blood \& Wine, was instead set in a very different visual environment. In order to justify the radical change of scenery, the setting changes from the Northern Realms to the florid and peaceful duchy of Toussaint. Unlike the war-ravaged Northern Realms, Toussaint is far from the horrors of war and the destruction that accompanies it. The architecture and landscape of Toussaint, as well as the toponyms, are inspired by France and Italy, bringing a different palette of colors to the game, in order to make it clear to the player that s/ he is in a different location. As explained by Kacper Niepokólczycki (2017):

Wild Hunt is the kind of game that is not the place you would like to go for a vacation. [...] It was kind of dark, grimish, dangerous and gory, and art had to support this. [...] on the other hand, as you saw on the teaser, Toussaint was very vibrant, very colorful. [...] Of course we got the basic idea from the books, but we got inspired by France and Italy. [..] Also, we had to create another city, which was different from Novigrad of the base game.

Beauclair is the capital of Toussaint and its architectural characteristics set it clearly apart from its counterpart Novigrad. It is not just the general visual style, a flamboyant Gothic, that marks the difference, but the complete lack of walls and fortifications in Beauclair is a clear message that signifies the peacefulness of the region. The absence of any kind of military fortification both in the capital as well as in the countryside demonstrates that there is no war going on, and also no social unrest within the duchy. Together with the distinct visual style, it is the lack of architectural features which we got used to in the rest of The Witcher 3 - but also in RPGs in general - that is semiotically relevant.

The "primary function" of virtual architecture does not differ from what we previously explained as regards informing the player about its utility and aiding her/ him in how to play the game or where to go. The "secondary function" however, as in the more symbolic meaning of architecture is the one that visually tells the player that $\mathrm{s} /$ he is now in a different place, without changing the range of possible actions, nor the way they are executed. The whole effort by the art team of $\mathrm{CD}$ 
Projekt RED was to communicate to the player the identity of the land of Toussaint and the city of Beauclair through its architectural design. Architectural details are once again, together with other environmental changes, such as the color palette, the signs that communicate the identity of the location. The inspiration for the location is Italy, France, as well as the city center of Kraków: "Renaissance architecture from Florence and Venice was very influential for us, because Novigrad is pure late medieval city, and so Toussaint should be a little bit further from [it] in historical period" (Dettlaff \& Niepokólczycki, 2016) says Marta Dettlaff, concept artist at CD Projekt RED. Kacper Niepokólczycki (Ballard et al., 2017), environment artist at CD Projekt RED, in an interview claims that as regards the architecture of Beauclair: "we had a huge folder with pictures of small, unique looking towns from across Italy", adding that:

Narrow streets full of beautiful and colourful vegetation and breath-taking architecture served as references for creating the renaissance-inspired look and feel of city [...] We also had plenty to draw upon for that here, in Kraków. The entirety of Old Town is a UNESCO World Heritage Site and rich in renaissance architecture. Our concept artists could literally go for a walk to the Main Square and grab a ton of references on the way.

This shows how the architectural design was carefully planned to convey a specific message of a city in a more advanced stage of historical development, Renaissance rather than Medieval, and how this message was delivered through the use of architectural references and details. The stone frames and cornices of doors, the pastel colors of the buildings, the belt courses on the facades are all architectural elements that help differentiate Beauclair from Novigrad, as they are usually present in classical and thus Renaissance architecture, rather than in the medieval one that characterizes Novigrad.

The fact that there is a discernible differentiation between the two locations demonstrates the strong semiotic component of virtual architecture, but there is also the fact that by changing the architectural design of a location, it was possible to convey a completely different mood, demonstrating how the "secondary function", the symbolic and communicative aspect of architecture in the opinion of Umberto Eco, is indeed present. Of course, there are limitless combinations with which a change of mood and tone can be achieved in an urban location. It goes without saying that a Renaissance city such as Beauclair, if ravaged by war and littered with corpses and fires can be definitely worse than a somewhat peaceful, even if less refined, Novigrad. It is not incidental that the developers showed exactly that during a scene in the game, when the city gets attacked by an army of vampires and other monstrous creatures, and the player has to revisit many of the parts of the city that $\mathrm{s} /$ he has previously explored, from the pristine state of before to the ravaged state during the attack. 


\section{Conclusion}

The semiotic component of virtual architectural design is visible on multiple levels in the digital game The Witcher 3. The built environment designed by the artists of CD Projekt RED exists not only to serve as a backdrop for the adventures of the player, but to communicate information as well. Umberto Eco considered that architecture is composed of "primary functions" that denotate what the architectural object is used for, and "secondary functions" that, built on the primary ones, have a symbolic connotative meaning and can vary based on the circumstances, users, and time periods. Virtual architecture proves to be no different, with primary functions that semiotically interact with the player, indicating situation and directions related to the gameplay and the action to perform, whereas secondary functions are an added value to the player's enjoyment and interpretation of the digital game. In the case of The Witcher 3, the artists and designers of CD Projekt RED decided to use architectural styles to further their idea of instilling a distinctive Eastern/Norther European style to the atmosphere of the game, and again, in the expansion Blood \& Wine, they used the same process to differentiate its locations from the ones of the base game.

\section{References}

1. Aarseth, E. (2001). Allegories of Space: The Question of Spatiality in Computer Games. In M. Eskelinen \& R. Koskimaa (Eds.), Cybertext Yearbook 2000 (pp. 152-171). Jyväskylä: Research Centre for Contemporary Culture, University of Jyväskylä.

2. Ballard, D. G., Domenech, M., \& Niepokolczycki, K. (2017, June 2). Déjà View: How Architecture Influences Our Favourite Game Worlds (J. Yarwood, Interviewer) [Kotaku UK]. Retrieved from http://www.kotaku.co.uk/2017/06/02/deja-view-how-architectureinfluences-our-favourite-game-worlds

3. BioWare. (2009-2014). Dragon Age (series) [Microsoft Windows, PlayStation 3, PlayStation 4, Xbox 360, Xbox One, OS X]. Canada: Electronic Arts.

4. CD Projekt RED. (2015). The Witcher 3: Wild Hunt [Microsoft Windows, PlayStation 4, Xbox One]. Poland: CD Projekt.

5. CD Projekt Red. (2015). The Witcher 3: Wild Hunt Artbook. Warsaw: CD Projekt Red.

6. CD Projekt RED. (2016). The Witcher 3: Wild Hunt-Blood and Wine [Microsoft Windows, PlayStation 4, Xbox One]. Poland: CD Projekt.

7. Dettlaff, M., \& Niepokólczycki, K. (2016). The Witcher 3: From Concept to Environment Art. Presented at the DevGAMM Conference, Minsk. Retrieved from https://www.you tube.com/watch?v=49gye22GZzw

8. Dzik, J. (2017, October 21). Polish Culture and Real Places in The Witcher 3 Wild Hunt. Retrieved February 22, 2018, from Plan Poland website: http://planpoland.com/realplac esinthewitcher/

9. Eco, U. (1997). Function and Sign: The Semiotics of Architecture. In N. Leach (Ed.), Rethinking Architecture: A Reader in Cultural Theory (pp. 173-193). London: Routledge. 
10. Eco, U. (2016). La struttura assente. La ricerca semiotica e il metodo strutturale. Milan: La nave di Teseo. (Original work published 1968)

11. Gygax, G., \& Arneson, D. (1974). Dungeons \& Dragons. TSR, Wizard of the Coast.

12. Jenkins, H. (2004). Game Design as Narrative Architecture. In N. Wardrip-Fruin (Ed.), First Person: New Media as Story, Performance, and Game (pp. 118-129). Cambridge, MA and London, UK: MIT Press.

13. Makuch, E. (2016, March 11). Witcher 3 Ships Almost 10 Million Copies-Report. Retrieved March 19, 2018, from GameSpot website: https:/www.gamespot.com/articles/ witcher-3-ships-almost-10-million-copies-report/1100-6435592/

14. Morolli, G. (2013). La lingua delle colonne. Florence: Edifir.

15. Niepokólczycki, K. (2017). Building Beauclair: Capital City in "The Witcher 3: Wild Hunt - Blood and Wine" Expansion Pack. Presented at the Game Developer Conference, Berlin. Retrieved from http://www.gdcvault.com/play/1023965/Building-Beauclair-CapitalCity-in

16. Origin Systems. (1981-1999). Ultima (series) [Apple II, Atari 8-bit, VIC-20, C64, DOS, MSX, FM Towns, NEC PC-9801, Atari ST, Mac OS, Amiga, Atari 800, NES, Master System, C128, SNES, X68000, PlayStation, Windows]. United States: Origin Systems.

17. Pellegrino, P., \& Jeanneret, E. P. (2009). Meaning of Space and Architecture of Place. Semiotica, 2009(175).

18. Sayed, R. (2015, April 27). Witcher 3 Map Size Compared to GTA5, Skyrim \& Far Cry 4, New Screens Show Different Visual Settings [GamingBolt]. Retrieved March 19, 2018, from https://gamingbolt.com/witcher-3-map-size-compared-to-gta5-skyrim-far-cry-4new-screens-show-different-visual-settings

19. Siabra-Fraile, J. (2009). Manic Miner under the Shadow of the Colossus: A Semiotic Analysis of the Spatial Dimension in Platform Video Games. E/C, Anno III(5), 67-74.

20. Square, Square Enix. (1987-2019). Final Fantasy (series) [Android, Arcade, BlackBerry OS, Windows Phone, Mobile phone, MSX, Nintendo 3DS, Nintendo DS, Game Boy Advance, Nintendo Entertainment System, GameCube, iOS, Ouya, PlayStation, PlayStation 2, PlayStation 3, PlayStation 4, PlayStation Portable, PlayStation Vita, Super Nintendo Entertainment System, Wii, Microsoft Windows, WonderSwan, Xbox 360, Xbox One]. Japan: Square Enix.

21. Stec, M., Marek, J., Gollent, M., Tost, M., \& Tomaszkiewicz, M. (2018, April). A Conversation with CD Projekt Red (P. Gaultier, Interviewer) [Heterotopias].

22. Tavinor, G. (2009). The Art of Videogames. Malden: Wiley-Blackwell.

23. Team Ico. (2001). Ico [PlayStation 2, PlayStation 3]. Japan: Sony Computer Entertainment.

24. thewitcher.com. (2016, August 11). Wiedźmin 3: Dziki Gon-Data premiery Edycji Gry Roku. Retrieved March 19, 2018, from The Witcher 3: Wild Hunt-Official Website website: http://thewitcher.com/pl/news/view/2059

25. Tolkien, J. R. R. (1954). The Lord of the Rings. London: George Allen \& Unwin. 
26. Tomaszkiewicz, K. (2015, May 8). The Witcher 3 on PS4 / Behind the scenes (K. Kujawska, Interviewer) [PlayStation Polska]. Retrieved from https://www.youtube.com/ watch?v=di3Zzp5yR_0

27. Upton, B. (2015). The Aesthetic of Play. Cambridge: MIT Press.

28. Vasari, G. (1986). Le vite de' piú eccellenti pittori, scultori ed architetti. Florence: Einaudi. (Original work published 1550) 